\title{
Assessment of breast self-examination practice and its associated factors among female undergraduate students in Addis Ababa University, Addis Ababa, Ethiopia, 2016
}

This article was published in the following Dove Medical Press journal:

Breast Cancer - Targets and Therapy

\author{
Mikiyas Amare Getu \\ Mesfin Wudu Kassaw \\ Kenean Getaneh Tlaye \\ Awet Fitiwi Gebrekiristos \\ Department of Nursing, Faculty of \\ Health Science, Woldia University, \\ Woldia, Ethiopia
}

Correspondence: Mikiyas Amare Getu Department of Nursing, Faculty of Health Science, Woldia University, PO Box 400, Woldia, Ethiopia

Emailmakmiky86@gmail.com
Background: Breast self-examination (BSE) is a simple, very low-cost, non-invasive early detection method used to detect breast cancer at early stage. It should be done for all women older than 20 years. The aim of this study was to assess BSE practice and associated factors among female undergraduate students in Addis Ababa University, Addis Ababa, Ethiopia.

Methods: Institution-based cross-sectional study design was conducted. Departments were selected from College of Business and Economics by using lottery method. A simple random sampling technique was used to select a total of 407 female students from each department. Data were collected by using structured self-administered and pretested questionnaire. Quantitative method was employed. Binary logistic regression and multiple logistic regressions were done to confirm association between variables.

Results: The finding of this study revealed that 87 (21.4\%) of the study participants have practiced BSE. Of whom, 45 (51.7\%) participants perform BSE every month and $9(10.5 \%)$ of the study participants perform BSE at the right time, which is 2-3 days after menstruation. Family history of breast cancer, knowledge, and attitude of BSE were found to be significantly associated with BSE practice.

Conclusion: This study revealed that majority of study subjects did not practice BSE. So, It's recommended that the concerned bodies create awareness around BSE and train students on how to practice BSE.

Keywords: practice, breast self-examination, female students, Addis Ababa University, breast cancer, early detection method

\section{Introduction}

Cancer is a major public health problem in many parts of the world. Breast cancer is a malignant tumor that starts from the cells of the breast. It occurs mostly in women, but men can also be affected. ${ }^{1}$

An estimated 231,840 new cases and 40,290 deaths of breast cancer are expected to occur among women in the US during 2015. ${ }^{2}$ In 2013, an estimated 232,340 new cases and 39,620 deaths from breast cancer are expected to occur in women. ${ }^{3}$ Breast cancer is one of the most commonly diagnosed cancers worldwide, which accounts for 1.7 million (11.9\%) in 2012, and there were 6.3 million women alive who had been diagnosed with breast cancer in the past 5 years. ${ }^{4,5}$

Unlike early detection in Western world, women in Ethiopia usually present late screening for breast cancer and are expected to have a very limited life span. The 
Oncologic service in Ethiopia is limited to only one Radiotherapy Center at Black Lion Specialized Hospital. ${ }^{6}$

Breast self-examination (BSE) is a simple, very low-cost, non-invasive early detection method used to detect early breast cancer, which involves the woman herself looking at and feeling for any change in their breast as early as possible, which yield a better survival rate. BSE should be done for all women older than 20 years. $^{7}$

In Ethiopia, breast cancer become fatal due to late presentation, limited resources, low awareness of breast cancer and its detection, symptoms, prevention, and strong traditional beliefs that can delay biomedical care. ${ }^{8}$ Therefore, many women miss early detection and treatment opportunities due to lack of information and knowledge of early detection of breast cancer.

The detection and treatment of reproductive organ cancers (ROCs), particularly breast cancer, is low. Despite its prevalence, ROCs are not managed as a major public health problem at any levels of health care delivery system. Nationwide, there is no organized ROC prevention, education, screening, or curative care program. Little is known about the scale of the problem, which makes it all the more difficult to formulate policies and/or develop practical strategies for dealing with it. ${ }^{8,9}$

According to Addis Ababa cancer registry reports, breast cancer accounts for $33 \%$ of all female cancer cases, followed by cervical cancer that accounts for $17 \%{ }^{10}$

A study conducted in Haramaya University, Ethiopia, had shown that majority of the students (77\%) had never performed BSE, even though they had good knowledge of BSE. Their reasons for this were as follows: absence of signs or symptoms (28.8\%), forgetfulness (17\%), fear of detecting some abnormality (16.4\%), and lack of privacy (15.4\%).

Regarding age of start for BSE, $41.37 \%$ of the study respondents started to perform BSE at the age of 20 years. Of the $23 \%$ of students who had done BSE, 16 (55.1\%) did not exactly remember how often they have done it, eight (27.5\%) practiced it yearly, one responder (3.44\%) has done BSE less than three times in last 12 months, four (13.79\%) performed BSE more than three times in the last 12 months. ${ }^{11}$

This study is important in providing information toward BSE practice among female undergraduate students. Better documenting students' BSE practice would be useful to governmental and non-governmental organization in the design of interventions aimed at effective prevention of breast cancer, and it may also encourage other researchers and policy makers to carry out a more extensive research in this particular area being as baseline data. This study is also considered vital because BSE can be a simple means through which early detection of a breast disease could be made. So assessing BSE practice will be helpful over scarce diagnostic service.

\section{Methods \\ Study setting}

This study was carried out in Addis Ababa University, College of Business and Economics. College of Business and Economics is under Addis Ababa University and consists of the former Faculty of Business and Economics and School of Commerce. School of Commerce in turn had seven departments. In 2015/2016, there were 3,221 students enrolled in the college. Among them, there were 350 female students from Faculty of Business and Economics and 590 from School of Commerce, comprising a total of 940 female undergraduate students.

\section{Study design, participants, and sampling procedure}

Institution-based cross-sectional study was used, and study participants were all female undergraduate students attending their education in selected departments in Addis Ababa University, College of Business and Economics. Sample size was determined using the formula for single population proportion with a $95 \% \mathrm{CI}$ and a precision of $5 \%$, and the prevalence was $59.5 \%$, which was taken from a research conducted in Mekelle University, Ethiopia. ${ }^{12}$

The calculated sample size was 370 , and by adding $10 \%$ non-response rate and incomplete lost questionnaire, the total sample size was found to be 407 students. The study subject again was selected proportionally to size allocation to give equal chance to each department, and then simple random sampling technique was performed. Data were collected using a pretested structured self-administered questionnaire.

The questionnaire contained five parts, comprising sociodemographic characteristics, history of breast cancer, knowledge, practice, and attitude about BSE.

\section{Data management and analysis}

BSE practice was assessed by requesting the respondents to answer six questions. Knowledge of BSE was assessed by 16 questions. Each correct response was scored 1, and incorrect response was scored 0 . The mean value was used to categorize students as having good knowledge or poor knowledge about BSE. Accordingly, the sum value less than the mean was categorized as poor knowledge, and the value greater than or equal to the mean was categorized as good knowledge. The possible score ranges from 0 to 16 . 
For items of attitude toward BSE, there were four negative attitude items and four positive attitude items. 5-point Likert scale (strongly agree/agree/neutral/disagree/strongly disagree) was used. For a positive attitude item, scores of “5”, “4”, “3”, " 2 ", and "1" denote "strongly agree", "agree”, "neutral", "disagree", and "strongly disagree", respectively. This scoring was reversed for the negative attitude items. The possible score for positive attitude item ranged from 8 to 40 . While for negative attitude items, the possible score ranged from 8 to 40 .

Data entry and validation were done using EpiData 3.1 statistical software (Odense M, Denmark) and then exported to SPSS windows version 21 (IBM Corporation, Armonk, NY, USA). Different frequency tables, graphs, and descriptive summaries were used to describe the study variables. Binary logistic regression was performed to assess the strength of association between each independent variable and the outcome variables. Those variables that show significant association with the outcome variable and $P$-value of $<0.2$ was included in multiple logistic regressions. Finally, only those independent variables that maintain association with outcome variables in multiple regressions were used to construct the final models. OR with its $P$-value of $0.05 \%$ and $95 \% \mathrm{CI}$ was used or reported in each logistic regression analysis.

\section{Ethical consideration}

This study was conducted after getting ethical clearance from institutional review board (IRB) committee of the Addis Ababa University. Permission was obtained from Addis Ababa University, College of Business and Economics. Informed verbal consent was obtained from the study and other concerned bodies to obtain their cooperation.

Participants' information obtained from the questionnaires was kept confidential. Participants were also informed that participation was voluntary and that they could withdraw from the study at any stage if they desired.

\section{Results}

\section{Sociodemographic characteristics}

A total of 407 students from Addis Ababa University, College of Business and Economics were enrolled in this study giving a respondent rate of $100 \%$. Majority of the respondents, $347(85.3 \%$ ), were in the age range of 20-22 years and $60(14.7 \%)$ were in the age group of 23 years and above. Regarding marital status, majority $387(95.1 \%)$ of the respondents were single. Of the total study participants, 342 $(84.0 \%)$ were from urban. One hundred seventy (41.8\%) of the study subjects were second year students, while the least $109(26.8 \%)$ were first year students. Two hundred fifty (61.4\%) of respondents' family average monthly income was above 3,501 Ethiopian Birr (ETB) (Table 1).

\section{History of breast cancer}

Majority of respondents, 366 (89.9\%), have reported that they did not have family history of breast cancer. Among respondents who had family history of breast cancer, 21 (51.2\%) of them were their aunts and $12(29.3 \%)$ were grandmothers. Only $13(3.2 \%)$ of respondents had personal history of breast cancer, and 99 (24.3\%) knew someone suffered from breast cancer (Table 2).

\section{Knowledge of study participants about BSE}

Of the total study participants' knowledge of BSE, 203(49.9\%) scored mean and above, which is good knowledge (Figure 3).

Two hundred eighty-three $(69.5 \%)$ of respondents mentioned that early detection of breast cancer improves the chance of survival. An assessment of the participant's knowledge of screening methods revealed that 220 (54.1\%) participants knew breast cancer screening methods, of whom 89 (21.9\%) knew types of breast cancer screening methods. Among participants who knew types of screening methods, 68 (56.2\%) of respondents knew BSE, 28 (23.1\%)

Table I Sociodemographic characteristics of female undergraduate students in Addis Ababa University, College of Business and Economics, Addis Ababa, Ethiopia, $2016(n=407)$

\begin{tabular}{|l|l|l|}
\hline Variables & Frequency & $\%$ \\
\hline Age (years) & & \\
\hline $20-22$ & 347 & 85.3 \\
\hline$\geq 23$ & 60 & 14.7 \\
\hline Marital status & & \\
\hline Single & 387 & 95.1 \\
\hline Married & 16 & 3.9 \\
\hline Divorced/separated & 4 & 1.0 \\
\hline Previous place of residence & & \\
\hline Urban & 342 & 84.0 \\
\hline Rural & 65 & 16.0 \\
\hline Year of study & & \\
\hline First year & 109 & 26.8 \\
\hline Second year & 170 & 41.8 \\
\hline Third year & 128 & 31.4 \\
\hline Family average monthly income (ETB) & & \\
\hline$<445$ & 12 & 2.9 \\
\hline $446-I, 200$ & 27 & 6.7 \\
\hline I,20I-2,500 & 79 & 19.4 \\
\hline $2,50 I-3,500$ & 39 & 9.6 \\
\hline$>3,501$ & 250 & 61.4 \\
\hline Abrevation ETB, Ethop & & \\
\hline
\end{tabular}

Abbreviation: ETB, Ethiopian Birr. 
Table 2 History of breast cancer among female undergraduate students in Addis Ababa University, College of Business and Economics, Addis Ababa, Ethiopia, 2016

\begin{tabular}{|l|l|l|}
\hline Variables & Frequency & $\%$ \\
\hline Family history of breast cancer $(\mathrm{n}=407)$ & & \\
\hline Yes & $4 \mathrm{I}$ & 10.1 \\
\hline No & 366 & 89.9 \\
\hline $\begin{array}{l}\text { Family member who had history of } \\
\text { breast cancer }(\mathrm{n}=4 \mathrm{I})\end{array}$ & & \\
\hline Mother & 7 & 17.1 \\
\hline Sister & $\mathrm{I}$ & 2.4 \\
\hline Grand mother & 12 & 29.3 \\
\hline Aunt & $2 \mathrm{I}$ & $5 \mathrm{I} .2$ \\
\hline Personal history of breast cancer $(\mathrm{n}=407)$ & & \\
\hline Yes & 13 & 3.2 \\
\hline No & 394 & 96.8 \\
\hline $\begin{array}{l}\text { Knows someone suffering from breast } \\
\text { cancer ( } \mathrm{n}=407)\end{array}$ & & \\
\hline Yes & 99 & 24.3 \\
\hline No & 308 & 75.7 \\
\hline
\end{tabular}

knew clinical breast examination, and 25 (20.7\%) knew mammography.

Two hundred seven $(50.9 \%)$ of the respondents had heard about BSE previously. Their predominant source of information was mass media (television/radio and magazines/newspapers), which accounts for 142 (64.3\%). One hundred thirty-one (32.2\%) of respondents correctly mentioned the appropriate age to begin BSE, ie, $\geq 19$ years of age.

\section{Practice of study participants toward BSE}

This study showed that only 87 (21.4\%) of the study participants ever practiced BSE, including 45 (51.7\%) participants who performed BSE every month, 13 (14.9\%) participants who performed once in a year, and $12(13.8 \%)$ participants who performed once in a week.

Of those practicing BSE only, 9 (10.5\%) of the study participants perform BSE at the right time, which is 2-3 days after menstruation (Figure 1 and Table 3).

The majority of the participants, 320 (78.6\%) who did not perform BSE, were further asked on their reasons for not performing BSE, and 95 (29.7\%) said that they did not know how to perform BSE, 81 (25.3\%) said that they do not have breast problem, 67 (20.9\%) of them said carelessness, and $48(15 \%)$ of them said forgetfulness (Figure 2).

\section{Attitude of study participants toward BSE}

The mean for total attitude score pertaining to BSE was 28.21. About half of the study participants, 206 (50.6\%) had a good attitude toward BSE (Figure 3).
BSE practice

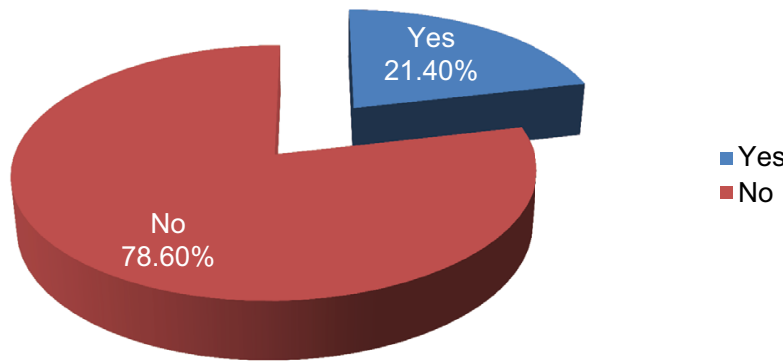

Figure I Breast self-examination practice among female undergraduate students in Addis Ababa University, College of Business and Economics, Addis Ababa, Ethiopia, 2016.

Table 3 Assessment of BSE practice among female undergraduate students in Addis Ababa University, College of Business and Economics, Addis Ababa, Ethiopia, 2016

\begin{tabular}{|c|c|c|}
\hline Variables & Frequency & $\%$ \\
\hline \multicolumn{3}{|l|}{ Ever performed BSE $(n=407)$} \\
\hline Yes & 87 & 21.4 \\
\hline No & 320 & 78.6 \\
\hline \multicolumn{3}{|l|}{ Frequency of performing BSE $(n=87)$} \\
\hline Once in a week & 12 & 13.8 \\
\hline Once in a month & 45 & 51.7 \\
\hline Once in 3 months & 7 & 8.0 \\
\hline Once in 6 years & 10 & 11.5 \\
\hline Once in a year & 13 & 14.9 \\
\hline \multicolumn{3}{|l|}{ Reason to perform BSE $(n=87)$} \\
\hline Had previous breast problem & 6 & 6.6 \\
\hline Fear of breast cancer from family history & 16 & 17.6 \\
\hline Recommended by health professional & 29 & 31.9 \\
\hline For early detection and treatment & 27 & 29.7 \\
\hline Fear of developing breast cancer & 13 & 14.3 \\
\hline \multicolumn{3}{|l|}{ Age when you start practicing BSE $(n=87)$} \\
\hline Less than 25 years & 70 & 80.5 \\
\hline Between 25 and 30 years & 10 & 11.5 \\
\hline Between 31 and 35 years & 2 & 2.3 \\
\hline Above 35 years & 5 & 5.7 \\
\hline \multicolumn{3}{|l|}{ The time you perform BSE $(n=87)$} \\
\hline $2-3$ days after session of menstruation & 9 & 10.5 \\
\hline When it comes to mind & 53 & 60.9 \\
\hline Regular days of each month & 7 & 8.0 \\
\hline Few days before menses & 5 & 5.7 \\
\hline Any time during the month & 13 & 14.9 \\
\hline
\end{tabular}

Note: a Total number is not equal to " $n$ " due to multiple response.

Abbreviation: BSE, breast self-examination.

\section{Factors associated with BSE practice}

To see the effect of independent variables on dependent variable (practice of BSE), bivariate and multivariate logistic regression analyses were carried out. The analysis was done by including sociodemographic characteristics, history 
of breast cancer, knowledge of BSE, and attitude of BSE. A result obtained from bivariate and multivariate logistic regression showed that family history of breast cancer and knowledge and attitude of BSE have a significant association with practice of BSE. Among study participants whose families had breast cancer, practice BSE 2.332 times more than study participants whose families didn't have his-

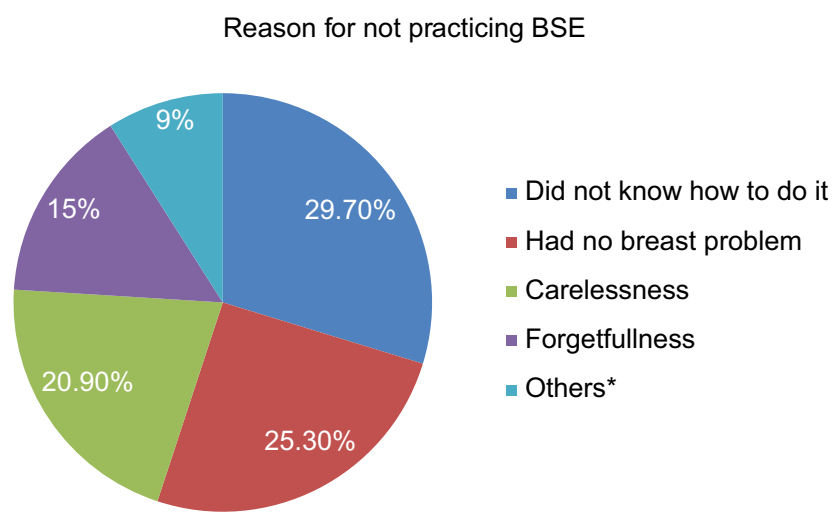

Figure 2 Reason for not practicing BSE among female undergraduate students in Addis Ababa University, College of Business and Economics, Addis Ababa, Ethiopia, 2016.

Note: *No benefit from practicing it, it is not comfortable, lack of privacy, fear of detecting abnormalities.

Abbreviation: AOR, adjusted odds ratio; BSE, breast self-examination. tory of breast cancer $(\mathrm{AOR}=2.332 ; 95 \% \mathrm{CI}, 1.009-5.389$, $P=0.048$ ).

Respondents who had good attitude toward BSE were 4.68 times more likely to practice BSE than those who have poor attitude $(\mathrm{AOR}=4.68 ; 95 \% \mathrm{CI}, 2.411-9.067, P \leq 0.001)$.

Those who had good knowledge toward BSE were 12.42 times more likely to practice BSE than those who had poor knowledge $(\mathrm{AOR}=12.422 ; 95 \% \mathrm{CI}, 5.478-28.167, P \leq 0.001)$ (Table 4).

\section{Discussion \\ BSE practice}

In this study, BSE practice was reported by $21.4 \%$ of study subjects, which is lower compared with study done among female health care professionals in Addis Ababa (75.1\%), Nursing female university students in Jordan (85\%), Ghana (76\%), Egypt (56.4\%), and Health extension workers in Gojam, Ethiopia (37.3\%). ${ }^{13-16}$

This discrepancy is because the study participants are nonhealth science students, never got the opportunity of training on breast cancer screening methods, and absence of any educational campaign regarding early detection of breast cancer, and unlike study participants in this study, nurses and other health care professionals have better awareness of how to perform BSE.

Overall knowledge and attitude toward BSE

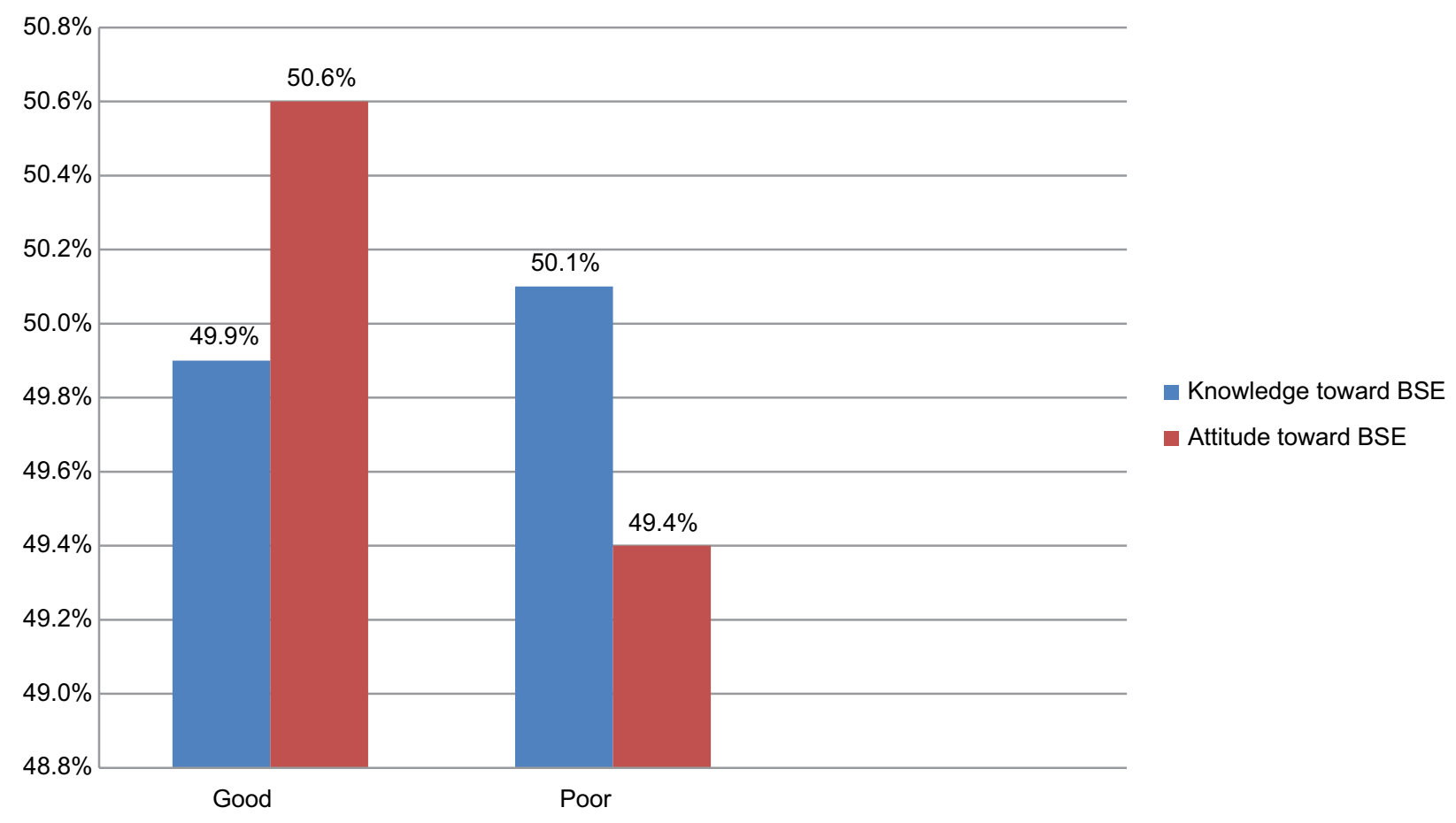

Figure 3 Overall knowledge and attitude of BSE among female undergraduate students in Addis Ababa University, College of Business and Economics, Addis Ababa, Ethiopia, 2016.

Abbreviation: BSE, breast self-examination. 
Table 4 Factors associated with BSE practice among female undergraduate students in Addis Ababa University, College of Business and Economics, Addis Ababa, Ethiopia, 2016

\begin{tabular}{|c|c|c|c|c|c|c|}
\hline \multirow[t]{2}{*}{ Variables } & \multicolumn{2}{|c|}{ BSE practice } & \multirow[t]{2}{*}{ COR $(95 \% \mathrm{Cl})$} & \multirow[t]{2}{*}{$P$-value } & \multirow{2}{*}{$\begin{array}{l}\text { AOR } \\
(95 \% \mathrm{CI})\end{array}$} & \multirow[t]{2}{*}{$P$-value } \\
\hline & $\begin{array}{l}\text { Yes, } \\
\text { n (\%) }\end{array}$ & $\begin{array}{l}\text { No, } \\
\text { n (\%) }\end{array}$ & & & & \\
\hline \multicolumn{7}{|c|}{$\begin{array}{l}\text { Family history of breast } \\
\text { cancer }\end{array}$} \\
\hline Yes & $15(36.6)$ & $26(63.4)$ & $2.36(1.19-4.68)$ & 0.014 & $2.33(1.01-5.39)$ & 0.048 \\
\hline No & $72(19.7)$ & $294(80.3)$ & 1.00 & & 1.00 & \\
\hline \multicolumn{7}{|c|}{$\begin{array}{l}\text { Personal history of breast } \\
\text { cancer }\end{array}$} \\
\hline Yes & $6(46.2)$ & $7(53.8)$ & $3.31(1.08-10.13)$ & 0.036 & $3.69(0.74-18.5 I)$ & 0.112 \\
\hline No & $81(20.6)$ & $313(79.4)$ & 1.00 & & 1.00 & \\
\hline \multicolumn{7}{|l|}{ Attitude toward BSE } \\
\hline Poor attitude & $17(8.5)$ & $184(9 \mid .5)$ & 1.00 & $<0.001$ & 1.00 & $<0.001$ \\
\hline Good attitude & $70(34.0)$ & $136(66.0)$ & $5.57(3.14-9.90)$ & & $4.68(2.4 \mathrm{I}-9.07)$ & \\
\hline \multicolumn{7}{|c|}{ Knowledge toward BSE } \\
\hline Poor knowledge & $9(4.4)$ & $195(95.6)$ & 1.00 & $<0.001$ & 1.00 & $<0.001$ \\
\hline Good knowledge & $78(38.4)$ & $125(61.6)$ & | $3.52(6.54-27.93)$ & & $12.42(5.48-28.17)$ & \\
\hline \multicolumn{7}{|c|}{$\begin{array}{l}\text { Knows someone suffering } \\
\text { from breast cancer }\end{array}$} \\
\hline Yes & $35(35.4)$ & $64(64.6)$ & $2.69(1.62-4.48)$ & $<0.001$ & $1.68(0.90-3.14)$ & 0.102 \\
\hline No & $52(16.9)$ & $256(83.1)$ & 1.00 & & 1.00 & \\
\hline
\end{tabular}

Abbreviation: AOR, adjusted odds ratio; COR, crude odds ratio; BSE, breast self-examination.

Similarly, a study conducted in Haramaya University had shown that majority of the students $(77 \%)$ had never performed BSE. ${ }^{11}$

From those ever practiced BSE, 51.7\% performed BSE on monthly basis, which is inconsistent with other studies done in Ghana (31\%) and Nigeria (17.1\%)..$^{14,17}$ The difference might be due to difference in educational status and accessibility to information.

In contrast to the finding of this study, a study conducted in Haramaya University had shown that $27.5 \%$ practiced BSE yearly. ${ }^{11}$ The discrepancy might be due to difference in the study area.

In this study, majority of students $(89.5 \%)$ did not perform BSE at the right time, ie, 2-3 days after menstruation. Two studies in Nigeria were congruent with this finding. ${ }^{17,18}$ In contrast to the above studies, $62 \%$ of students in Ghana perform BSE at appropriate time, which was some days after menstruation. ${ }^{14}$ The gap is because study participants in Ghana were nursing students who had better experience and knowledge on BSE.

In this study, the main reasons for not doing BSE were lack of knowledge how to perform BSE, had no breast problem, carelessness, and forgetfulness. Similarly, in the study conducted in Gojam, Ethiopia, the three main reasons for not doing BSE were: had no breast problems; did not know BSE technique and not knowing the importance of BSE. ${ }^{16}$
Female students in north western Nigeria mentioned forgetfulness and belief that there is no problem with their breast as reasons for not practicing BSE. ${ }^{19}$ While students in Haramaya University listed their following reasons: have no signs or symptoms, forgetfulness, fear of detecting some abnormality, and lack of privacy. ${ }^{11}$ The reason for lack of knowledge how to perform BSE has been mentioned in this study and another study conducted in Gojam but not in a study conducted among students in Haramaya University and in Ahmadu Bello University in Northwestern Nigeria, and this might be due to having a better knowledge on BSE techniques.

\section{Factors associated with BSE practice}

In this study, a significant relation had been found between BSE practice and family history of breast cancer, knowledge, and attitude of BSE. Study participants with family history of breast cancer perform BSE 2.33 times more than participants without family history of breast cancer ( $\mathrm{AOR}=2.332 ; 95 \%$ CI, 1.009-5.389), which was consistent with a study done in Northwest Nigeria ${ }^{19}$ and Kuwait. ${ }^{20}$ In contrast to this study, family history of breast cancer had not significant association with BSE practice in a study conducted in Malaysia. ${ }^{21}$

Those who had a good knowledge toward BSE were more likely to practice BSE than those who had poor knowledge $(\mathrm{AOR}=12.42 ; 95 \%$ CI, 5.478-28.167). 
In line with this finding, studies conducted in Iran, Jordan, and Malaysia reported significant association between knowledge and practice of BSE. On the other hand, personal history of breast cancer did not show significant association with BSE practice similar to this study. ${ }^{13}$

In this study, respondents who had good attitude toward BSE perform BSE 4.675 times more than respondents with poor attitude $(\mathrm{AOR}=4.675 ; 95 \% \mathrm{CI}, 2.411-9.067)$. This study was almost in line with evidence in Iran and Malaysia. ${ }^{22,23}$ This could be explained by attitude towards BSE which can have an affect on BSE practice.

Other sociodemographic variables such as age, marital status, previous place of residence, department of study, year of study, family average monthly income, and father and mother educational status were not found to be significantly associated with BSE practice. On contrary to this study, a study conducted in north western Nigeria explained that regular performance of BSE was significantly associated with duration of stay in the university; students who had spent more years in the university were more likely to practice BSE. ${ }^{19}$ Another study conducted among nursing female university students in Ghana had also shown the association between the educational level of the student and the ability to perform BSE. The ability to perform BSE improved as the educational level is higher. ${ }^{14}$ The discrepancy might be that the participants in this study were non-health science students. So their longer stay in university or educational level could not bring improvement on their BSE practice because breast cancer-related issues were not included in their lesson, absence of educational material that had adequate information about breast cancer screening method and absence of programs for awareness creation about breast cancer.

\section{Conclusion}

The result of this study demonstrated that less than one-fourth of participants, 87 (21.4\%), practiced BSE. Ethiopian Cancer Association and Ministry of Health should prepare breast cancer early detection measures training packages to health care professionals who could play a key role in educating the public. Effective health education campaigns should be prepared to elucidate awareness and practice of BSE to students. Establishments of a club by trained BSE awareness peer group at the campus to improve practice of BSE. Information about BSE should be provided to the general public through different media platforms such as television, radio, and magazines, and facilitate social media platforms as a means of disseminating information on BSE.

\section{Author contributions}

All authors contributed toward data analysis, drafting and revising the paper, gave final approval of the version to be published and agree to be accountable for all aspects of the work.

\section{Disclosure}

The authors report no conflicts of interest in this work.

\section{References}

1. American Cancer society [homepage on the Internet]. Breast Cancer; 2014. Available from: https://www.cancer.org/content/dam/cancer-org/ research/cancer-facts-and-statistics/annual-cancer-facts-and-figures/2014/ cancer-facts-and-figures-2014.pdf. Accessed November 28, 2018.

2. American Cancer society [homepage on the Internet]. Cancer Facts \& Figures 2015; Vol. Special Se. 2015. Available from: https://cancer.org/ research/cancer-facts-statistics/all-cancer-facts-figures/cancer-factsfigures-2015.html. Accessed November 28, 2018.

3. American Cancer Society. Breast Cancer Facts and Figures 2013-2014. Atlanta: American Cancer Society, Inc. 2013.

4. World Health Organization. Latest World Cancer Statistics. France: International Agency for Research Cancer. 2013.

5. American Cancer Society [homepage on the Internet]. Cancer in Africa. International Agency for Research Cancer. 2008. Available from: http:// http://globocan.iarc.fr. Accessed November 28, 2018.

6. Anderson BO, Shyyan R, Eniu A, et al. Breast cancer in limited-resource countries: an overview of the Breast Health Global Initiative 2005 guidelines. Breast J. 2006;12(Suppl 1):S3-S15.

7. Burke KM, LeMone P, Mohn-Brown EL. Medical-Surgical Nursing Care. 2nd ed. Prentice Hall: Pearson; 2007.

8. Dye TD, Bogale S, Hobden C, Tilahun Y, Deressa T, Reeler A. Experience of initial symptoms of breast cancer and triggers for action in ethiopia. Int J Breast Cancer. 2012;2012:1-5.

9. Federal Democratic Republic of Ethiopia Ministry of Health. National Reproductive Health Strategy. Ministry of health; 2006-2015.

10. AFCRN [webpage on the Internet]. Ethiopia-Addis Ababa city cancer registry. Available from: http://afcrn.org/membership/membershiplist/100-addisababa. Accessed February 12, 2016.

11. Ameer K, Abdulie SM, Pal SK. Breast cancer awareness and practice of breast self-examination among female medical students in haramaya University, Harar, Ethiopia. Int J Interdiscip Multidiscip Stud. 2014;2(2): 109-119.

12. Hailu T, Berhe H, Hailu D, Berhe H. Knowledge of breast cancer and Its early detection measures among female students, in Mekelle University, Tigray Region, Ethiopia. Sci J Clin Med. 2014;3(4):57-64.

13. Petro-Nustus W, Mikhail BI. Factors associated with breast self-examination among jordanian women. Public Health Nurs. 2002;19(4):263-271.

14. Sarfo LA, Awuah-Peasah D, Acheampong E. Knowledge, attitude, and practice of self-breast examination among female university students at Presbyterian University College, Ghana. Am J Res Commun. 2013;1(11): 395-404.

15. Elshamy KF, Shoma AM. Original article knowledge and practice of breast cancer screening among Egyptian Nurses. African J Haematol Oncol. 2010;1(December):122-128.

16. Azage M, Abeje G, Mekonnen A. Assessment of factors associated with breast self-examination among health extension workers in West Gojjam Zone, Northwest Ethiopia. Int J Breast Cancer. 2013;2013:1-6.

17. Omoyeni OM, Oluwafeyikemi PE. Assessment of the knowledge and practice of breast self examination among female cleaners in Obafemi Awolowo University Ile Ife, Nigeria. Int J Caring Sci. 2014;7(1):239-251. 
18. Faronbi JO, Abolade J. Breast self examination practices among female secondary school teachers in a rural community in Oyo State, Nigeria. Open J Nurs. 2012;02(02):111-115.

19. Gwarzo UM, Sabitu K, Idris SH. Knowledge and practice of breast-self examination among female undergraduate students of Ahmadu Bello University Zaria, northwestern Nigeria. Ann Afr Med. 2009;8(1):55-58.

20. Alazmi SF, Alkhabbaz A, Almutawa HA, Ismaiel AE, Makboul G, ElShazly MK. Practicing breast self-examination among women attending primary health care in Kuwait. Alexandria J Med. 2013;49(3):281-286.
21. Akhtari-Zavare M. Knowledge on breast cancer and practice of breast self examination among selected female university students in Malaysia. Med Health Sci J. 2011;7(1804-1884):49-56.

22. Montazeri A, Vahdaninia M, Harirchi I, et al. Breast cancer in Iran: need for greater women awareness of warning signs and effective screening methods. Asia Pac Fam Med. 2008;7(1):6-7.

23. Rosmawati NHN. Knowledge, attitude and practice of breast self-examination among women in a Suburban Area in Terengganu, Malaysia. Asian Pacific J Cancer Prev. 2010;11:1503-1508.
Breast Cancer - Targets and Therapy

\section{Publish your work in this journal}

Breast Cancer - Targets and Therapy is an international, peerreviewed open access journal focusing on breast cancer research, identification of therapeutic targets and the optimal use of preventative and integrated treatment interventions to achieve improved outcomes, enhanced survival and quality of life for the cancer patient.

\section{Dovepress}

The manuscript management system is completely online and includes a very quick and fair peer-review system, which is all easy to use. Visit http://www.dovepress.com/testimonials.php to read real quotes from published authors.

Submit your manuscript here: https://www.dovepress.com/breast-cancer---targets-and-therapy-journal 